\title{
Water and dementia, learning from clinical experience
}

\author{
Aziz VM' ${ }^{*}$ and Roufael $\mathbf{R}^{2}$ \\ ${ }^{1}$ Devon partnership NHS Trust, North Devon District Hospital, Meadow View ward, Barnstaple EX31 4JB, UK \\ ${ }^{2}$ Speciality Trainee (ST4), Wales Deanery, UK
}

\begin{abstract}
In every day practice, at home, in care homes, and in inpatient settings people with dementia may encounter negative experience with water. In this reflection, we try to look at some learning points from clinical practice.
\end{abstract}

\section{Water}

Water is the most life-sustaining substance, and it is necessary for good health including regulating body temperature, maintaining blood volume, maintaining blood pressure and eliminating bodily waste and toxins, as well as helping the biochemical reactions that occur in the brain cells to take place. We use it frequently for hydration, bathing, and cleaning. People with dementia sometimes develop a fear of water as part of their condition and understanding the possible reasons for it can help us find new ways to address their anxiety.

\section{Dementia and water}

Dementia is a syndrome associated with a progressive decline of cognitive functioning, which goes beyond the normal impairment and deterioration associated with old age. Some of the theoretical causes of dementia included environmental factors such as exposure to solvents and the presence of metals and pesticides causing contamination of drinking water [1]. While many contaminants are found at levels not enough not to cause immediate illness, it is possible that exposure to those contaminants will, over time, impact on various illnesses such as liver damage, cancer.

While tap water is treated thoroughly to reduce pollution, some contaminants may still remain including heavy metals, chemicals, microbes, and pharmaceuticals drugs. Some of the elements found in drinking water include arsenic, lead, cyanide, fluoride, acyclamide, mercury, chlordane, oxamyl, toulene, trichlorothene, bromate, aluminium, lithium and xylemes which may have some effect on the brain. The precise role of those elements in neurological disorders is, however, controversial [2-6].

Bondy and Campell (2018) [7] reviewed water quality and its impact on brain function. They observed that exposure during later stages of lifespan including increase in oxidative stress and inflammation may compound age-related deterioration of CNS performance. Adding to that exposure to water and environmental contaminants may pose a risk for increased incidence of slow progressing diseases that are generally associated with aging or impaired development.

The blood-brain barrier protects the brain by filtering any harmful agents before the blood reaches it. Aluminium does not pass through easily but when combined e.g. with fluoride will. Water supply often is treated with aluminium sulphate and aluminium fluoride, both of which combine very easily in the blood. Aluminium competes with calcium for absorption; this could cause a build-up of aluminium in the bloodstream. It is possible to consider that sufficient quantities built up in the brain over a period could possibly lead to cognitive impairment such as Alzheimer's disease [8].

\section{Dehydration}

Water is lost daily through perspiration, salivation and urination. Fluid has to be replaced to prevent dehydration. While the overall risk of dehydration can increase with age, the risk is particularly acute for people who suffer dementia. Even mild dehydration can start to have an effect on people, causing tiredness, headaches and a lack of concentration. But in more severe cases, it can cause confusion, delirium and in the very worst-case scenarios, death. Many people with dementia will already have days where they seem very confused, and other days where they're more lucid, so knowing when these symptoms might be caused by dementia, versus dehydration can be difficult.

Dehydration can be a common challenge for people with dementia, particularly if they are also elderly. Older people especially with cognitive impairment may forget to drink regularly. However, sometimes the satiety and thirst centres in the brain may not work properly. So, they may be feeling parched, but not actually realise that the feeling they have is thirst, and that taking a drink would help with it. In the later stages of dementia, it can become harder to swallow, and this can lead to choking or dribbling and a loss of fluid. Limited mobility either because of dementia or due to another health condition, such as arthritis or rheumatism, may make the person struggle to get up from a chair or bed regularly to get a drink. Another factor is the possible side-effects of medications especially anticholinergic or diuretic effects.

There are steps that can be taken to help prevent dehydration such as: making it as easy as possible for your loved one to have regular drinks of water or other fluids throughout the day by placing cups and

${ }^{\star}$ Correspondence to: Victor M Aziz, Devon partnership NHS Trust, North Devon District Hospital, Meadow View ward, Barnstaple EX31 4JB, UK, E-mail: victoraziz@doctors.org.uk

Key words: water, dementia, dehydration, fear, delusion

Received: April 01, 2019; Accepted: April 10, 2019; Published: April 15, 2019 
jugs of water in areas around the house. If they have limited dexterity or co-ordination, and struggle to drink from a cup, a water bottle with an easy-to-open top, non-spill cups or one-way straws can help to maintain hydration levels and will help to prevent spillage and maintain dignity.

Gentle nudges to remind them to have a drink regularly by putting up notices around the house or trying an Ulla (smart and stylish little gadget can be attached to a glass, bottle or jug and will remind the person to drink every 30-40 minutes). Also, provide high water content food such as broth, apples, oranges, berries, grapes, watermelon, cucumber and cottage cheese $[9,10]$.

\section{The fear of water}

Aquaphobia is considered a specific phobia "an abnormal and persistent fear of water. Specific phobia can be linked to cardiac diseases, gastrointestinal diseases, respiratory diseases, arthritic conditions, migraine, and thyroid diseases [11]. Suffers of water phobia experience anxiety even though they realize the water may pose no imminent threat. They generally avoid such activities as boating and swimming. Around the house, they may fear the water in a shower and even desist from bathing. For other people the experience of being hoisted can be distressing. Some people may experience panic attacks and can be quite debilitating and embarrassing.

Some people suffering from fear of water have had a bad experience in the past. Somehow, they had a negative possibly scary past experience with water that has made them afraid. Some people may react with alarm during bath time out of embarrassment especially if they still retain feelings regarding privacy and appropriate behaviour. Hence, bath time is often traumatic for older adults who are embarrassed to have help during this delicate part of the day. Others who have previously fallen on a slippery surface may associate water with painful injuries.

It is important to approach people slowly, practicing deep breathing and relaxation exercises and encourage the person and celebrate the achievements, no matter how small, and accept that overcoming the fear is a process and a journey that takes time and patience.

\section{Delusional ideation}

It could be the water, feeling cold, fear of falling, maybe it's a chore, or maybe someone with dementia feels very physically and/or emotionally vulnerable. By the time someone's dementia has reached a point that they begin to refuse bathing the dementia prevents them from being able to articulate what it is that bothers them about it. Delusions about water intoxication have been associated with depressive features and psychiatric illness $[12,13]$.

In people with dementia it is important to remember that dementia affects a person's pain, temperature and visual perception $[14,15]$. For example, a person with dementia may be afraid to step on wavy or dark spots on the floor because they think they are holes in the ground or snakes. This skewed sense of perception also impacts how they view water. Since water is clear, it can look invisible to people with dementia, which may make it unappealing to drink. Dementia alters how people feel certain things, and sensory input is often heightened. Many older adults become more sensitive to temperatures in their environment because of aging skin. The altered sensations experienced by people with dementia can make this even more pronounced. They may fear water if they perceive it to be too cold or hot. Many of people with dementia simply don't understand what water is and then it represents a danger for them. This may affect their dignity if they cannot be kept clean.

\section{Case}

Someone who lived in a nursing home screamed in terror before bath time. They had a wonderful, warm, massaging walk-in bath but the bubbles in the water made the person think they were going to be boiled. Water in general seems to be a problem and fear plus lack of understanding seem to be at the bottom of the behaviour. The caregiver helped to calm, soothe, reassure and praise the person. Asking the person to help them along by holding something like a washcloth can help. They told the person step by step what they are going to do and keeping private areas covered. Making sure the room/bath is warm, big soft and fluffy towels, scented soaps, and they adjusted the temperature to a more comfortable setting i.e. trying to make it a positive experience.

\section{References}

1. Killin LO, Starr JM, Shiue IJ, Russ TC (2016) Environmental risk factors for dementia: a systematic review. BMC Geriatr 16: 175. [Crossref]

2. Wills MR, Savory J (1985) Water content of aluminum, dialysis dementia, and osteomalacia. Environ Health Perspect. 1985; 63:141-147. [Crossref]

3. Sparks DL, Friedland R, Petanceska S, Schreurs BG, Shi J, et al. (2006) Trace copper levels in the drinking water, but not zinc or aluminum influence CNS Alzheimer-like pathology. J Nutr Health Aging 10: 247-254. [Crossref]

4. Kim HY, Kim HV, Yoon JH, Kang BR, Cho SM, et al. (2014) Taurine in drinking water recovers learning and memory in the adult APP/PS1 mouse model of Alzheimer's disease. Sci Rep 4: 7467. [Crossref]

5. Knudsen NN, Schullehner J, Hansen B, Jørgensen LF, Kristiansen SM, et al (2017) Lithium in Drinking Water and Incidence of Suicide: A Nationwide Individual-Level Cohort Study with 22 Years of Follow-Up. Int J Environ Res Public Health 14: 627. [Crossref]

6. Wu F, Jasmine F, Kibriya MG, Liu M, Cheng X, et al. (2015) Interaction between arsenic exposure from drinking water and genetic polymorphisms on cardiovascular disease in Bangladesh: a prospective case-cohort study. Environ Health Perspect 123 : 451-457. [Crossref]

7. Bondy SC, Campbell A (2017) Water Quality and Brain Function. Int J Environ Res Public Health 15. [Crossref]

8. Yokel RA. Aluminium and Alzheimer's disease. The Science that Describes the Link 2001, Pages 233-260. Chapter 12 - Aluminium and the Blood-Brain Barrier. https://doi org/10.1016/B978-044450811-9/50037-9. Accessed 15/3/19

9. Bunn DK, Abdelhamid A, Copley M, Cowap V, Dickinson A, et al. (2016) Effectiveness of interventions to indirectly support food and drink intake in people with dementia: Eating and Drinking Well IN dementia (EDWINA) systematic review. BMC Geriatr 16: 89. [Crossref]

10. Abdelhamid A, Bunn D, Copley M, Cowap V, Dickinson A, et al. (2016) Effectiveness of interventions to directly support food and drink intake in people with dementia: systematic review and meta-analysis. BMC Geriatr 16: 26. [Crossref]

11. Witthauer C, Ajdacic-Gross V, Meyer AH, Vollenweider P, Waeber G, et al. (2016) Associations of specific phobia and its subtypes with physical diseases: an adult community study. BMC Psychiatry 16: 155. [Crossref]

12. Lai J, Lu Q, Xu Y, Hu S (2016) Severe water intoxication and secondary depressive syndrome in relation to delusional infestation. Neuropsychiatr Dis Treat 12: 517-521. [Crossref]

13. Ferrier IN (1985) Water intoxication in patients with psychiatric illness. Br Med J (Clin Res Ed) 291: 1594-1596. [Crossref]

14. Fletcher PD, Downey LE, Golden HL, Clark CN, Slattery CF, et al. (2015) Pain and temperature processing in dementia: a clinical and neuroanatomical analysis. Brain 138: 3360-3372. [Crossref]

15. Khundakar AA, Hanson PS, Erskine D, Lax NZ, Roscamp J, et al. (2016) Analysis of primary visual cortex in dementia with Lewy bodies indicates GABAergic involvement associated with recurrent complex visual hallucinations. Acta Neuropathol Commun 4: 66. [Crossref]

Copyright: (C2019 Aziz VM. This is an open-access article distributed under the terms of the Creative Commons Attribution License, which permits unrestricted use, distribution, and reproduction in any medium, provided the original author and source are credited. 